\title{
Risk assessment framework for Mediterranean airports: a focus on extreme temperatures and precipitations and sea level rise
}

\author{
Carmela De Vivo ${ }^{1}$ D . Marta Ellena ${ }^{2,3}$. Vincenzo Capozzi ${ }^{1} \cdot$ Giorgio Budillon ${ }^{1}$. \\ Paola Mercogliano ${ }^{2}$
}

Received: 9 January 2021 / Accepted: 5 October 2021 / Published online: 21 October 2021

(C) The Author(s) 2021

\begin{abstract}
The increase of frequency and severity of extreme weather events due to climate change gives evidence of severe challenges faced by infrastructure systems. Among them, the aviation sector is particularly at risk from the potential consequences of climate change. Airports are classified as critical infrastructures because they provide fundamental functions to sustain societies and economic activities. More specifically, Mediterranean airports face risks associated with sea level rise, higher occurrence of extreme temperature and precipitation events. These aspects require the implementation of appropriate risk assessments and definition of targeted adaptation strategies, which are still limited in the Mediterranean region. The aim of the present paper is to provide theoretical frameworks in order to assess risks of climate change on Mediterranean airports, related to extreme temperature, extreme precipitation and sea level rise. Starting from a review of the literature, we first identify the sources of climate risk that may induce potential impacts on airports, here divided in air side and land side components. In order to do so, we select a series of indicators used as proxies for identifying hazard, exposure and vulnerability. The application of these theoretical frameworks allows defining the level of risk associated to each hazard, with the goal to support the identification of specific adaptation measures for the Mediterranean airports.
\end{abstract}

Keywords Airports $\cdot$ Climate change $\cdot$ Mediterranean area $\cdot$ Resilience $\cdot$ Risk assessment

Carmela De Vivo

carmela.devivo001@studenti.uniparthenope.it

1 Department of Science and Technology, University of Naples "Parthenope", Centro Direzionale di Napoli - Isola C4, 80143 Naples, Italy

2 Regional Models and Geo-Hydrological Impacts Division (REMHI), Fondazione CMCC-Centro Euro-Mediterraneo Sui Cambiamenti Climatici, Caserta, CE, Italy

3 Department Environmnetal Sciences, Informatics, and Statistics, University of Venice "Ca Foscari”, 30172 Mestre, Italy 


\section{Introduction}

Climate change may have negative impacts not only on natural systems but also on anthropogenic ones (IPCC 2014). More recently, the scientific community has focused on analysing the impacts of extreme events on critical infrastructures including transportation systems such as bridges, roads, airports and motorways (EU-CIRCLE 2016; Forzieri et al. 2018; Marios et al. 2019).

In fact, the intensification of extreme events due to climate change poses a high risk to infrastructures. Therefore, their adaptation to the climate of the future is necessary. The scientific community has made available numerous services to support adaptation and mitigation policies. One example is the Copernicus Climate Change Services (C3S), which provide society with authoritative information on past and future climate in Europe and in the rest of the world, with the aim of supporting adaptation policies in several sectors, including critical infrastructures. On the other hand, European policy has also focused on these issues. Indeed, one of the objectives of the European Green Deal is the modernization of European critical infrastructures to make them more resilient to climate risk as well. Critical infrastructures are essential for the proper functioning of a State's economic and social system and an interruption of services could cause serious damage. In this context, airports play a unique and significant role in the world transportation system through the facilitation of mobility and the promotion of economic growth (Burbidge 2016). However, due to their vulnerability to severe weather conditions, airports are particularly exposed to the potential consequences of climate change (Burbidge 2016; Lopez 2016; Christodoulou and Demirel 2018). In fact, extreme weather phenomena can lead to an interruption of airport services, determining significant economic impacts. For example, for some major airports, a closure may cost more than 1 million dollars per hour (Christodoulou and Demirel 2018). According to the "Challenges of Growth 2013" report, published by the European Organization for the Safety of Air Navigation (called Eurocontrol), the key risks of climate change for the European aviation sector are due to temperature increases, extreme precipitations, changes to storm and wind patterns, sea level rise and storm surges (Eurocontrol 2013). In addition, although the impacts on European airports differ according to the geographical area, climate zones and local circumstances (EEA 2017a), the greatest risks are expected in central and southern Europe. Airports located in the Mediterranean area are more likely to face risks related to extreme temperatures, extreme rainfall events and sea level rise (if located on the coasts and no more than $3 \mathrm{~m}$ above sea level), compromising their correct functioning (Eurocontrol 2013). More specifically, extreme summer temperatures lead to heat damages on runway and apron surfaces (Burbidge 2016) and, in addition, they may have negative effects on the maximum take-off weight by affecting aircraft performance, resulting in cargo restrictions (Burbidge 2018; Gratton et al. 2019). Limiting cargo implies serious economic losses for airlines: restrictions of $4 \%$ are equivalent to giving up 12-13 passengers (Coffel et al. 2018). Moreover, heavy precipitation events and sea level rise compromise airports' drainage capacity. Runways, taxiways and electrical infrastructure could suffer from severe flooding with consequent disruption of services and considerable economic damage (Burbidge 2016 2018; ICAO 2019). To date, in the European context, several projects have been launched to encourage airports conducting risk assessments and in order to cope with consequences of climate change (PESETA III project, 2018 (Christodoulou and Demirel 2018); VULCLIM project, 2016 (Lopez 2016); Colin et al. 2016). However, these risk assessments do not consider indicators related to sensitivity and adaptive capacity, key factors for risk analysis introduced in the Fifth Assessment 
Report of IPCC 2014 (Oppenheimer et al. 2014). In addition, the aviation sector has long been criticized for contributing to the causes of climate change through greenhouse gas emissions, but the need for aviation to adapt to the consequences of climate change has not been well researched or considered (Burbidge 2018; Ryley et al. 2020) and the methodologies for risk assessment are still limited, especially in the Mediterranean area (Gratton et al. 2020; Ryley et al. 2020). The present work proposes a methodology to define the level of climate risk on airport infrastructures in the Mediterranean regions. According to the framework proposed by IPCC 2014 (Oppenheimer et al. 2014), and other studies in the field (Forzieri et al.2016, 2018; Allen et al. 2018; Das et al. 2020; Ellena et al. 2020; Shah et al. 2020), risk is here defined as a function of hazard, exposure and vulnerability, which is in turn divided in sensitivity and in adaptive capacity. Based on updated information from the literature, we first identified the sources of climate risk that induce potential impacts on airports. Subsequently, for each hazard we selected a series of indicators used as proxies for identifying exposure to climate risk and vulnerability characteristics.

The proposed methodology considers all components involved in airport risk assessment (i.e. hazard, exposure and vulnerability). This aspect constitutes the main element of novelty with respect to previous methodologies proposed by the literature, which offered only a partial evaluation of risk that did not include sensitivity and adaptive capacity factors. The paper is organized as follows. Section 2 describes the methodology used to structure the risk assessment frameworks related to extreme temperatures, extreme precipitations and sea level rise with each specific component included within the climate hazard, the exposure and the vulnerability factor. In Sect. 3, we present and discuss the theoretical frameworks proposed, while in Sect. 4 we synthesize the key findings, highlighting the main challenges for future research.

\section{Material and methods}

\subsection{A conceptual framework for airports risk assessment over Mediterranean regions}

The general concepts of risk, risk assessment and risk management are nowadays established in many fields, from technical applications to project management, finance industry or civil protection (GIZ 2017). Generally, in the scientific literature, the most accepted and the broadest definition of risk is that given by ISO Norm 31,000 (ISO 2009), which defines risk as "the potential occurrence of events and consequences (impacts) or a combination of these" (GIZ, 2017). However, since this paper is focused on the risk arising from climate hazards, we decided to use the definition proposed by IPCC in the Fifth Assessment Report (AR5) of 2014, which specifically refers to the risks deriving from climate change (IPCC 2014). The framework proposed by IPCC (2014) estimates the climate risk as a combination of hazard $(\mathrm{H})$, exposure $(\mathrm{E})$, sensitivity and adaptive capacity (Oppenheimer et al. 2014; Carrão et al. 2016; Ellena et al. 2020; Shah et al. 2020). Unlike the risk assessment defined in ISO Norm 31,000, where the results obtained are compared with tolerability/ acceptability criteria ("risk evaluation phase"), in the IPCC AR5 they are generally categorized into five risk classes: very low, low, intermediate, high, very high (IPCC 2014).

In this context, hazard refers to the potential occurrence of climatic events that could damage the airport and compromise its operations. The exposure sample refers to the airport components that may be affected and damaged by major hazard events. Sensitivity is 
intended as the degree to which the system is (positively or negatively) affected by a certain climate exposure (Zebisch et al. 2017), while adaptive capacity refers to the ability to adapt to climate change or to cope with the consequences (Oppenheimer et al. 2014; Ellena et al. 2020). Generally, to define the components of risk, indicators that describe a specific phenomenon and its evolution are commonly used (Master Adapt 2018). These indicators may have a direct relationship with the phenomenon to be measured or an indirect relationship. In fact, in the absence of direct measurements the indicator represents the phenomenon itself (Master Adapt 2018). With regard to climate indices, they describe the climate and its changes over time due to anthropogenic factors, whereas impacts and vulnerability indicators are useful to assess the consequences of climate change and the capacity of environmental and socio-economic systems to cope with it. Based on these concepts, the risk assessment framework was built as follows. First, we defined the climate hazards affecting airports in Mediterranean areas, here divided in extreme temperatures, extreme rainfall and sea level rise (Eurocontrol 2013). For each hazard, specific indices were selected to analyse the variations in frequency and intensity of high impact events. Then, we identified the exposure samples, here defined as two major fields related to air side and land side (Alba and Manana 2016). Finally, we selected specific sensitivity and adaptive capacity indicators based on the exposure sample under analysis. In order to calculate the risk index, it was necessary to normalize these indicators. The aim of normalization is to transform the values of the indicators, measured at different scales and in different units, into comparable values, disconnected from units of measurement as to be considered on a common scale (Master Adapt 2018). This approach simply transformed all values to scores in a range from 0 to 1 , where the value 0 represents the optimal level, while the value 1 the more critical ones.

Figure 1 shows in different colours each risk component with the respective indicators.

\subsection{Hazard: extreme temperatures, extreme precipitations and sea level rise}

For the construction of the frameworks, we focused on three climate risks: extreme temperatures, extreme rainfall and sea level rise. In fact, the Mediterranean regiondefined as a climate hot spot by Giorgi (2006) — will be affected by the intensification of these phenomena that will therefore compromise aviation operations and airport infrastructures (Eurocontrol 2013; ICAO 2019). For each hazard, as explained in previous sections, we selected specific indicators that describe the variability of the climatic extremes in terms of frequency and intensity (see Table 1). We considered both absolute and percentile-based threshold indices. The indices related to extreme temperature events were defined using specific thresholds collected in the literature (Coffel and Horton 2015; Coffel et al. 2018; Monioudi et al. 2018; Borsky and Unterberger 2019). These thresholds describe the climatic conditions under which physical damages to infrastructures might occur and airport operations could be impaired. To define extreme precipitation events, we used percentile-based threshold indices (Borsky and Unterberger 2019) as well as indicators based on return periods (Forzieri et al. 2018). Return period indicators are often used in the context of extreme natural events and they are commonly used to quantify and communicate the upcoming risks. Forzieri et al. (2018) associate a specific intensity class to the event considered based on return time (TR): very high (TR $\geq 100 \mathrm{yr}$ ), high ( $100 \mathrm{yr}>\mathrm{TR} \geq 50 \mathrm{yr})$, moderate (50 yr $>\mathrm{TR} \geq 20 \mathrm{yr}$ ), low $(20 \mathrm{yr}>\mathrm{TR} \geq 10 \mathrm{yr})$, very low $(10 \mathrm{yr}>\mathrm{TR} \geq 2 \mathrm{yr})$ or no hazard $(2 \mathrm{yr}>\mathrm{TR})$. Higher TRs $(100,150$ years) are used to define intense events that could lead to massive damage and 


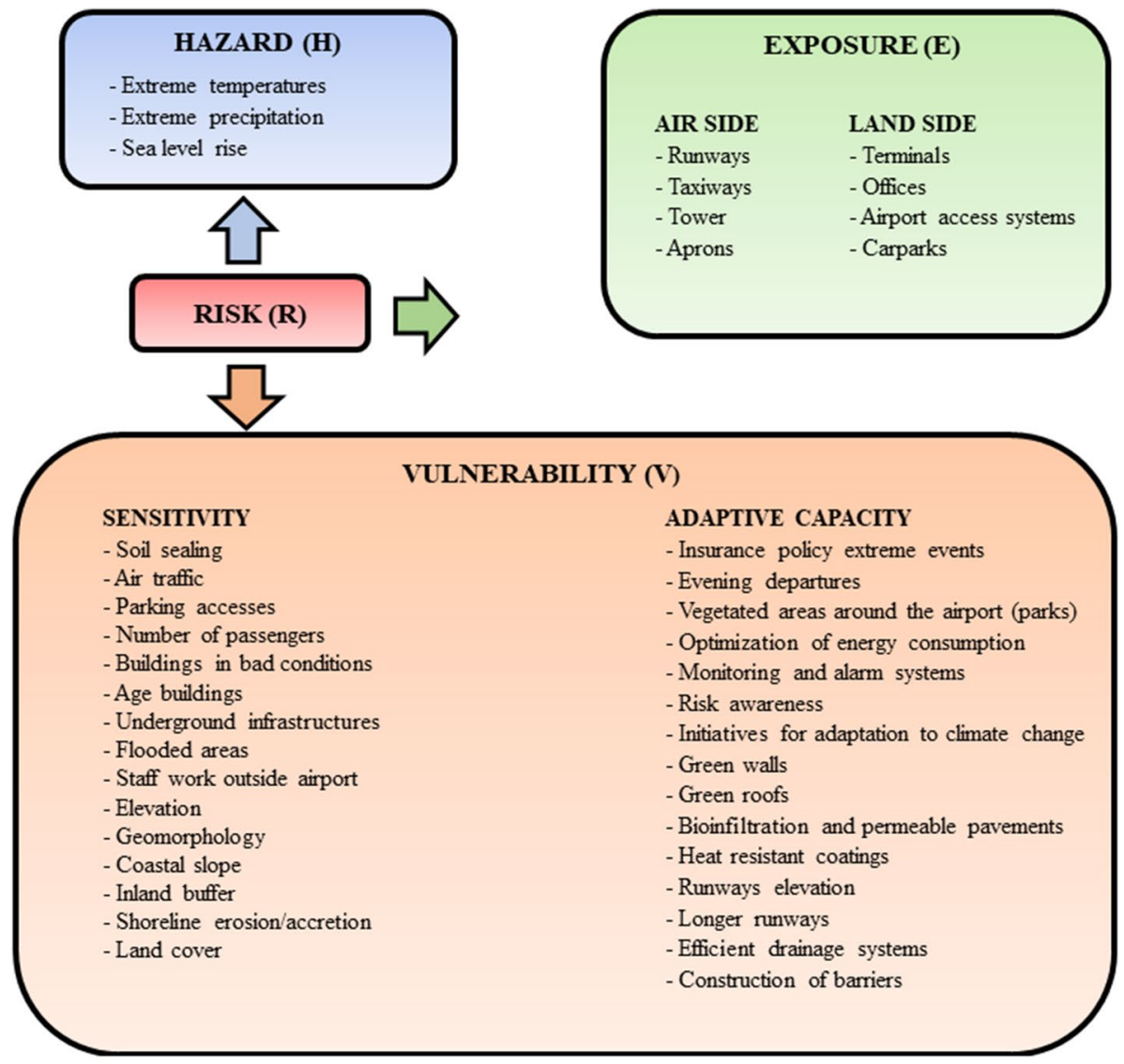

Fig. 1 A risk assessment framework for mediterranean airports: hazard, exposure and vulnerability components

human loss. On the other hand, a low TR $(10,20,50$ years) defines events that cause moderate damage. In relation to sea level rise, we selected two different indicators that describe coastal flooding: sea level rise (SLR) and storm surge level (SSL) (Oppenheimer et al. 2014; EEA 2017b; SNPA 2018). SLR is defined as the potential increase of mean sea level that may cause permanent or occasional inundation of low-lying coastal areas (Özyurt and Ergin 2009). SSL is defined as the temporary increase (at a particular locality) of sea level due to extreme meteorological conditions (Özyurt and Ergin 2009; Ragazzo 2017). The storm surge indicator, therefore, corresponds to the height reached by sea level during an extreme event of a specific return period (e.g. 5, 10, 20, 50 or 100 years). Therefore, through the combination of these indices, it is possible to estimate the increase in the potentially flooded coastal area in relation to storm surges with a specific return time and sea level rise based on the analysed climate scenario (Özyurt and Ergin 2009). Data about future scenarios of sea level rise and storm surges should be integrated with the data concerning the topography of the territory (Digital Land Model (DEM)), the distance from the coast and the presence of artificial reefs. 


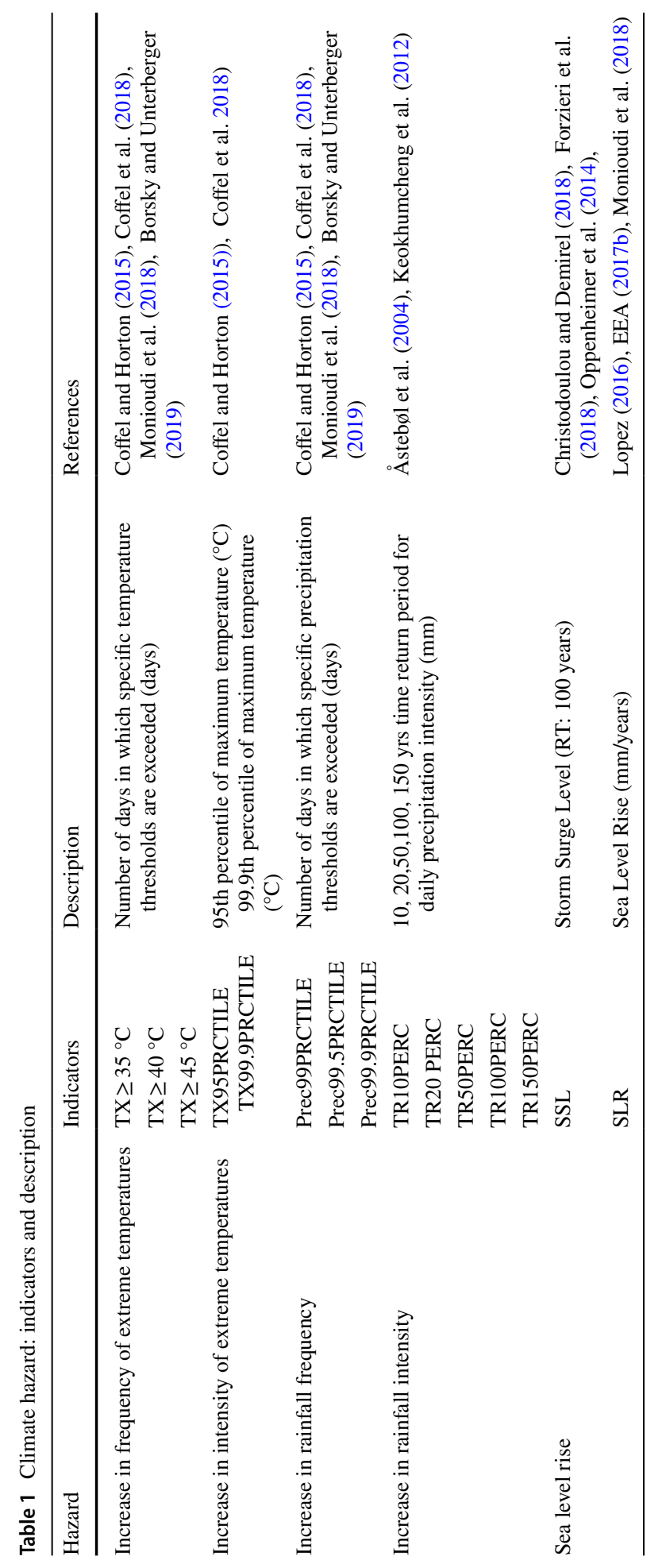




\subsection{Exposure: air side and land side components}

When performing a risk assessment, it is necessary to accurately define which assets are threatened, i.e. the exposed samples. We considered the various airports components as exposed samples. From an operational point of view, the airport is generally divided into two main areas of activity: the landside and airside activities (Alba and Manana 2016). In general, the air side components include the structures used for the movement of aircraft, such as runways, taxiways, tower and aprons. On the other hand, the land side components refer to the public access areas such as offices, terminals, airports access systems and parking areas (see Table 2). The considered climate risks determine direct and indirect impacts on the exposed samples. In the present study, direct impacts refer to damages of airports elements (runways, taxiways, buildings, etc.), while indirect impacts do not directly refer to the exposed samples, but they may cause indirect problems within interdependent resources (e.g. delays, cancellation or economic losses) (Ashley et al. 2005; Ellena et al. 2020). The various components of the airport may suffer different damages based on the hazard considered (Lopez 2016). In fact, the various structures of an airport are interconnected, and the interruption of the services offered by a single component can create criticalities in other activities within the airport. For example, if the runway is damaged due to high temperatures, there may be delays or cancellations of flights or in the worst cases the closure of the airport. In this context, identifying the elements most exposed to the damage associated with climate risk is essential in order to implement targeted adaptation strategies.

\subsection{Sensitivity and adaptive capacity factors (vulnerability)}

After identifying the climate hazards and the exposure sample, we identified sensitivity indicators (see Table 3). Here, "sensitivity" refers to how much the asset or system is susceptible when exposed to a specific climate hazard (Forzieri et al. 2018). The sensitivity indicators are influenced by natural, physical, socioeconomic and morphological characteristics of the system and depend on the type of impact to be assessed (Master Adapt 2018). The physical factors actively influence the sensitivity of the system while the social factors can indirectly affect the vulnerability to climate impacts. Among the physical indicators, those concerning the characteristics of the structures (such as age and condition of the asset) were selected. Indeed, older structures may have been built to outdated design standards thus making them more vulnerable to extreme events. Furthermore, assets in bad condition are more likely to be damaged when subjected to climatic stress (Rowan et al. 2014). The percentage of impervious surfaces (Master Adapt 2018) may also influence the response of the system to heavy precipitations (more likely flooding and runoff) or to extreme temperatures (overheating due to the absorption of solar radiation). As far as social indicators are concerned, we selected air traffic, the number of passengers passing through the airport and the respective accesses to the parking areas. In fact, it will be more difficult to manage these impacts due to extreme climate events in a very busy airport. Finally, we identified geological and socio-economic indicators, such as the morphology and the land cover of a specific place. These factors influence the airport's vulnerability to extreme climatic events, especially with regard to sea level rise (Dismukes and Narra 2016; Hamid et al. 2019). These indicators are also used in the calculation of the Coastal Vulnerability Index (CVI), which is one of the most common used methods to assess coastal vulnerability to sea level rise, in particular due to erosion and/or inundation (McLaughlin et al. 2010). 


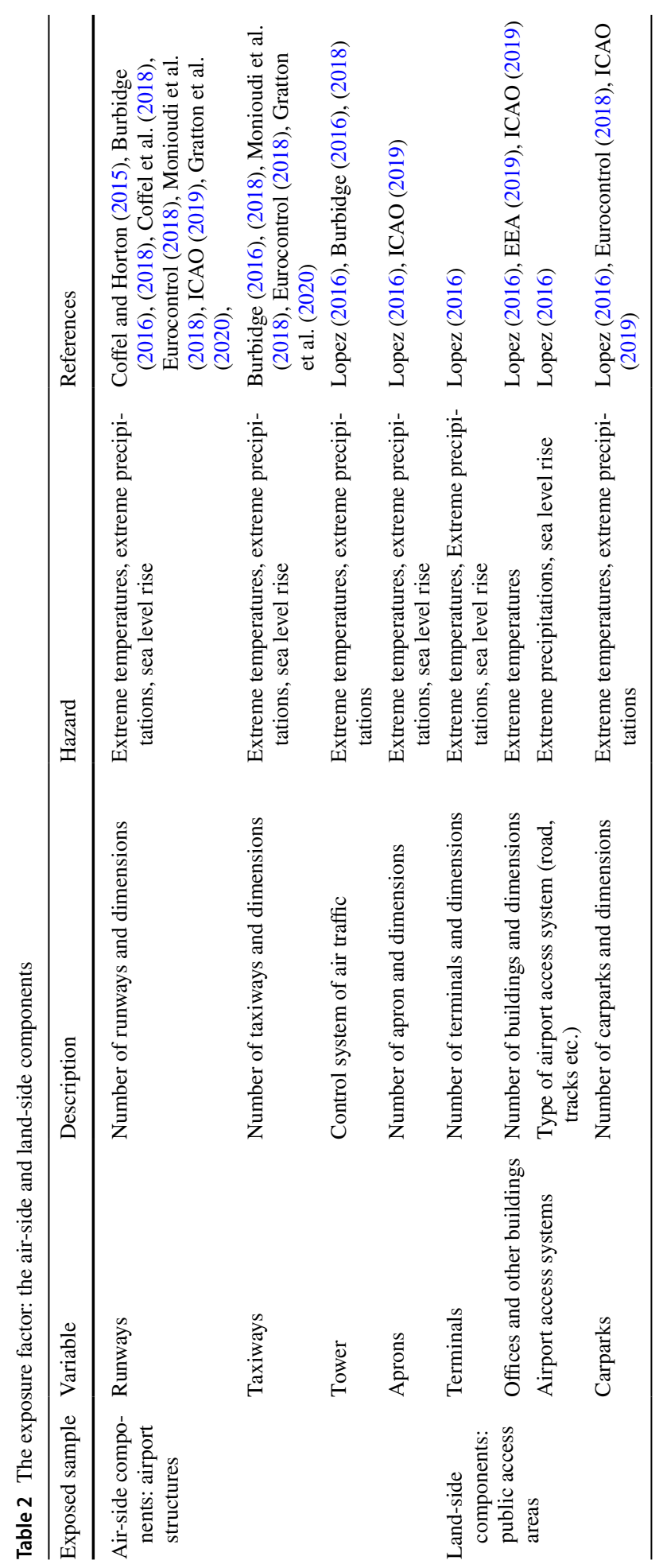




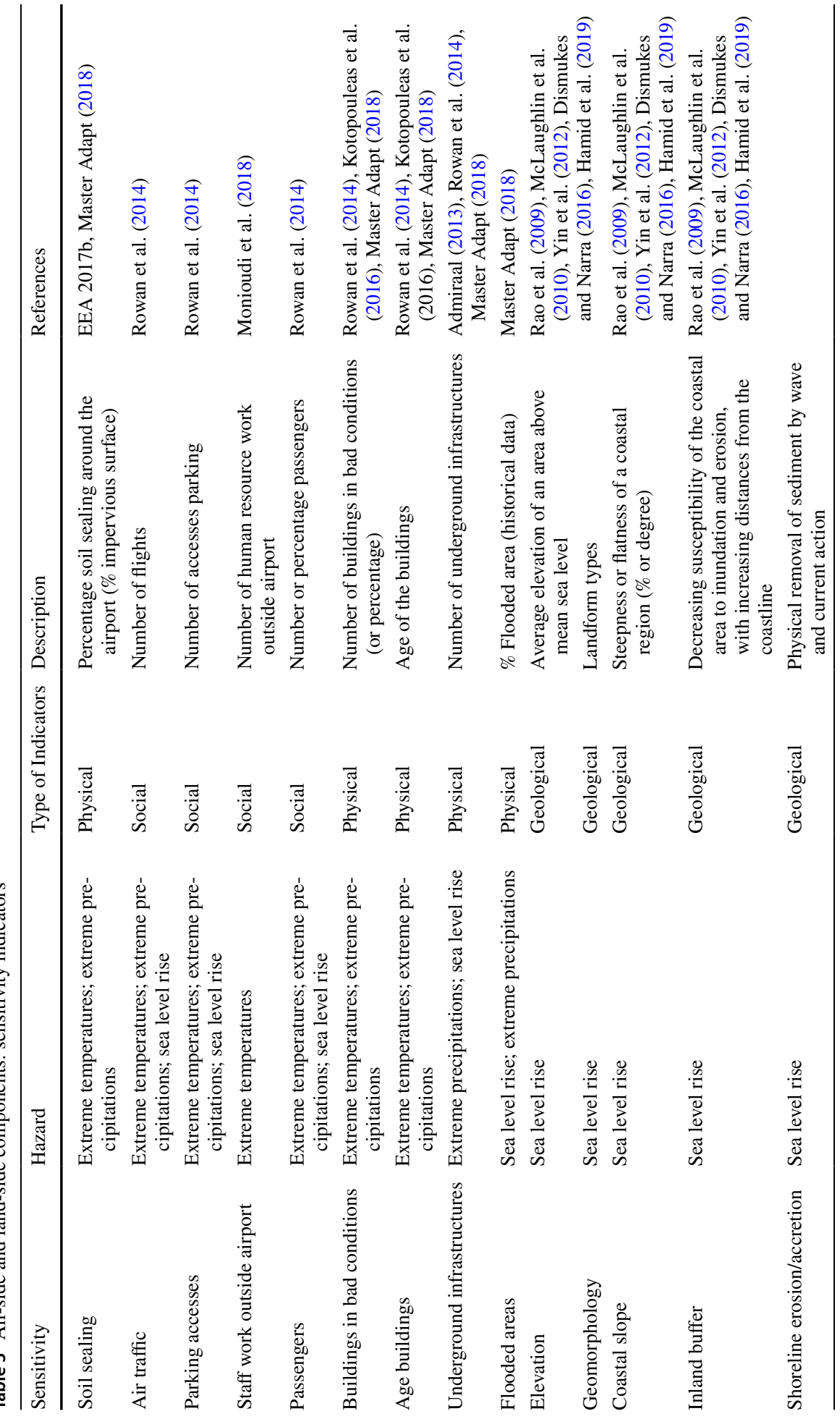




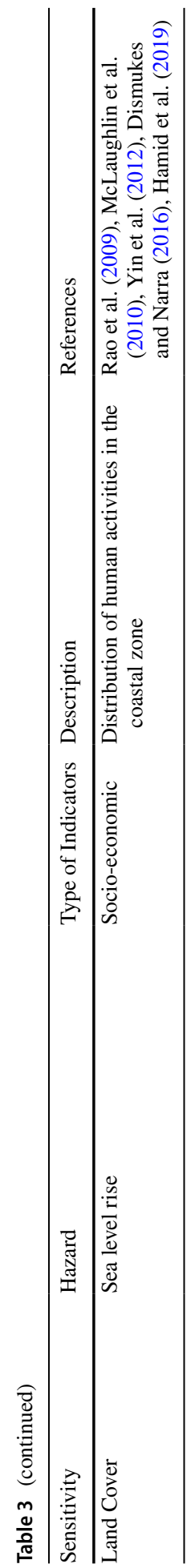


Table 3 shows details on the indicators used to define sensitivity of airport components based on the chosen hazard. In parallel, we selected the adaptive capacity indicators (see Table 4) that reflect the characteristics of airport components, which make them more or less likely to respond to expected damages. The adaptation strategies implemented to cope with climate change can be of a physical, social, institutional, technological and economic type (Master Adapt 2018). The adaptive capacity of a specific system, as well as all the previous considered factors, is defined in relation to each expected impact based on the hazards considered. Often, adaptation options can be categorized in grey, green and soft measures (Climate-ADAPT Platform). Grey measures refer to technological and engineering solutions aimed at improving the adaptation of territories, infrastructures and population. Soft actions include managerial, legal and political measures that change human behaviour and governance styles. Finally, green measures are based on the ecosystem-based (or nature-based) approach and make use of multiple services provided by natural ecosystems to improve resilience and adaptation capacity (Climate-ADAPT platform). With regard to climate adaptation of airports, soft measures refer to the enhancement of alert systems, the promotion of awareness campaigns about climate risk for managers, employees and passengers, the development and updating of emergency management plans, adherence to insurance policies for extreme events as well as initiatives for the optimization of energy consumption (Colin et al. 2016; Burbidge 2018; ICAO 2019). Grey measures include the construction of improved drainage systems to cope with flooding due to intense rainfall or the construction of barriers and runways elevation to cope with storm surges and sea level rise (ICAO 2019). On the other hand, green actions refer to development and enhancement of green areas around the airport (for example parks) or to installation of roofs and walls with vegetation on the existing airport structures to mitigate the effects related to extreme temperatures (Shafique and Kim 2017).

\subsection{Standardisation of indicators and calculation of the risk index}

Once the indicators for each component of the risk have been identified and calculated, the next step involves calculating the climate hazard index $(\mathrm{H})$, the exposure index $(\mathrm{E})$ and the vulnerability index (V). These indices are calculated starting from the normalization of each indicator. Metric indicators (e.g., temperature, precipitation) are generally normalized by applying the Min-Max method (Ellena et al. 2020). This approach simply transforms all values to scores in a range from 0 to 1 , where the highest value corresponds to the highest contribution for each factor (and vice versa). The nominal or category indicators (non-numerical) are instead normalized through their attribution into five classes, in which the lowest class represents optimal conditions and the highest one more critical conditions, according to the scheme present in Master Adapt (2018). The values obtained are then transformed into a range of values from 0 to 1 to be comparable with the other metric indicators. However, in some cases the range of values of the indicators is not the same. For example, for adaptive capacity indicators, lower values should indicate conditions positive for vulnerability while higher values negative conditions (the greater the ability to minor adaptation is vulnerability). In this case, the range of values of the indicator must be inverted in order to have them all in the same normalization ranking (Ellena et al. 2020). The calculation of each index takes place through an aggregation, using linear aggregation method. During the aggregation phase, it is possible to assign a weight (w) to each indicator that identifies their greater (or lesser) influence within the evaluation. In case of lack of information from scientific 


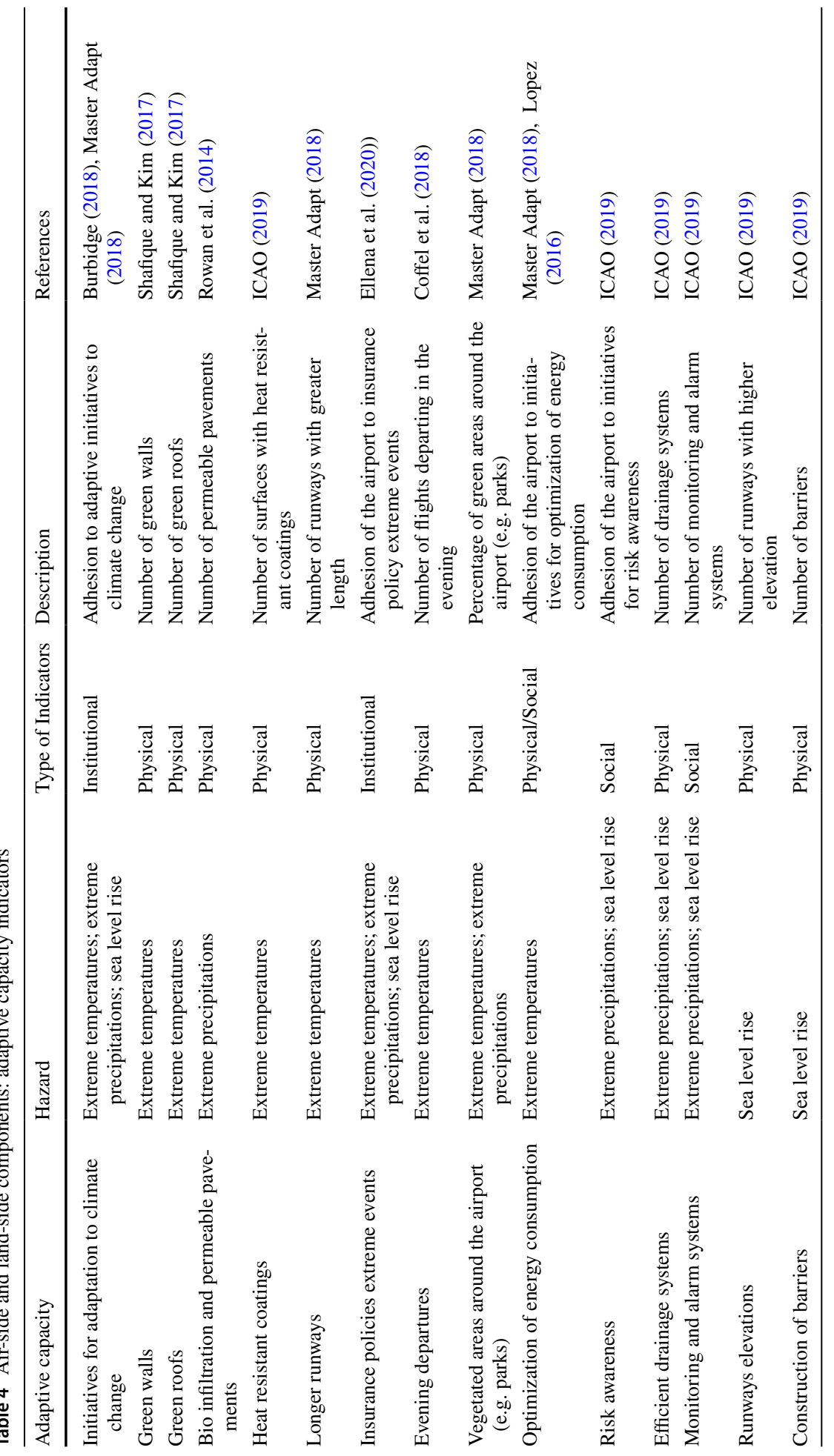


literature or due to the complexity of the analysed process, the value 1 can be assigned as a weight for each indicator. The risk index is given by the multiplication of hazard, exposure and vulnerability index. The Vulnerability Index formula implies a simple average between sensitivity and adaptive capacity indices. In the case of vulnerability indicators concerning sea level rise, the information for the calculation of the CVI must be integrated (see paper McLaughlin et al. 2010). For more details on the normalization of the indicators and the calculation of the risk index, see the paper Ellena et al. (2020) and Master Adapt (2018).

\section{FRAMEWORK 1: RISK

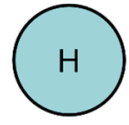

$\mathrm{X}$

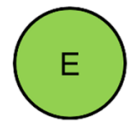

$\mathrm{X}$

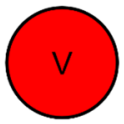

\section{CLIMATE HAZARD INDICATORS UNIT \\ Increase in frequency of $\mathrm{TX} \geq 35^{\circ} \mathrm{C} \quad$ days/year \\ extreme temperatures $\quad \mathrm{TX} \geq 40^{\circ} \mathrm{C} \quad$ days/year}

$\mathrm{TX} \geq 45^{\circ} \mathrm{C} \quad$ days/year

Increase in intensity of $\quad$ TX95PRCTILE $\quad{ }^{\circ} \mathrm{C}$

extreme temperatures $\quad$ TX99.9PRCTILE $\quad{ }^{\circ} \mathrm{C}$

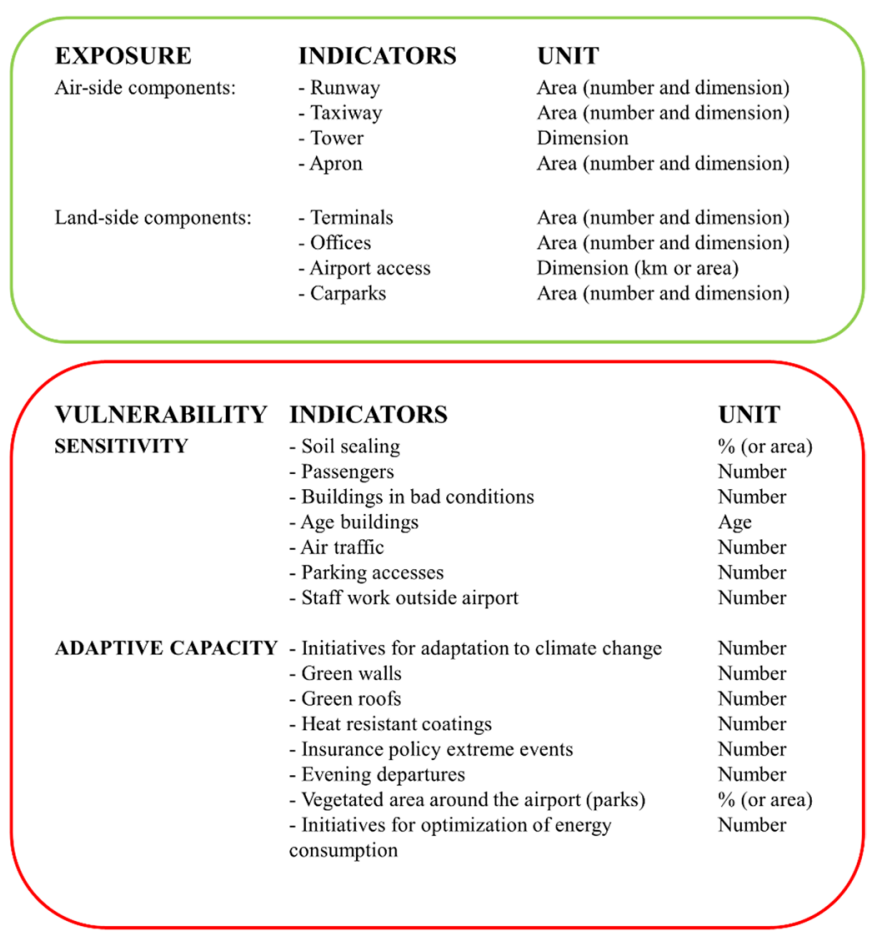

Fig. 2 Framework 1- Climate risk due to extreme temperatures 


\section{Results and discussion}

In this section, we present and discuss the risk frameworks obtained (Fig. 2, Fig. 3 and Fig. 4). The exposed samples are the same for each analysed hazard. In framework 1 (in Fig. 2), the selected climate indices are based on temperature thresholds that may damage runway surfaces, aprons, taxiways, parking areas or that may cause an interruption of airport activities (Burbidge 2016, 2018; Lopez 2016; ICAO 2019). For example, in July 2018 the north runway of Hanover Airport (Germany) was severely damaged due to temperatures above $+36{ }^{\circ} \mathrm{C}$, resulting in a cancellation of 41 flights. Furthermore, the extreme temperatures can also interfere with the take-off capacity of aircraft, which depends on the prevailing weather conditions and on the characteristics of the runway (Coffel and Horton

\section{FRAMEWORK 2: RISK \\ DUE TO EXTREME \\ PRECIPITATIONS}

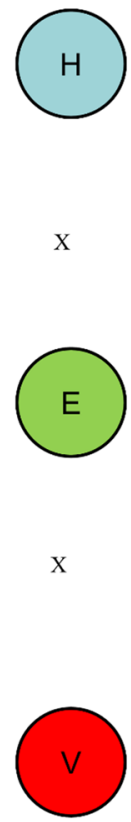

\begin{tabular}{|lll|}
\hline CLIMATE HAZARD & INDICATORS & UNIT \\
Increase in rainfall frequency & Prec99PRCTILE & $\begin{array}{l}\text { days/year } \\
\text { days/year } \\
\text { days/year }\end{array}$ \\
& Prec99.5PRCTILE & \\
& & \\
Increase in rainfall intensity & PR10PRCTILE & $\mathrm{mm}$ \\
& PR20PRCTILE & $\mathrm{mm}$ \\
& PR50PRCTILE & $\mathrm{mm}$ \\
& PR100PRCTILE & $\mathrm{mm}$ \\
& PR150PRCTILE & $\mathrm{mm}$ \\
\hline
\end{tabular}

\section{EXPOSURE}

Air-side components:

INDICATORS

- Runway

- Taxiway

- Tower

- Apron

Land-side components: $\quad$ - Terminals

- Offices

- Airport access

- Carparks

\section{UNIT}

Area (number and dimension)

Area (number and dimension) Dimension

Area (number and dimension)

Area (number and dimension)

Area (number and dimension) Dimension ( $\mathrm{km}$ or area) Area (number and dimension)

\begin{tabular}{|lll|}
\hline VULNERABILITY & INDICATORS & UNIT \\
SENSITIVITY & - Soil sealing & $\%$ (or area) \\
& - Passengers & Number \\
& - Buildings in bad conditions & Number \\
& - Age buildings & Age \\
& - Air traffic & Number \\
& - Parking accesses & Number \\
& - Underground infrastructures & Number \\
& - Flooded areas & Number (or \%) \\
& & \\
ADAPTIVE CAPACITY & - Initiatives for adaptation to climate change & Number \\
& - Vegetated area around the airport (e.g., parks) & $\%$ (or area) \\
& - Insurance policy extreme events & Number \\
& - Risk awareness & Number \\
& - Efficient drainage system & Number \\
& - Monitoring and alarm system & Number \\
& - Bioinfiltration and permeable pavements & Number \\
\hline
\end{tabular}

Fig. 3 Framework 2-Climate risk due to extreme precipitations 


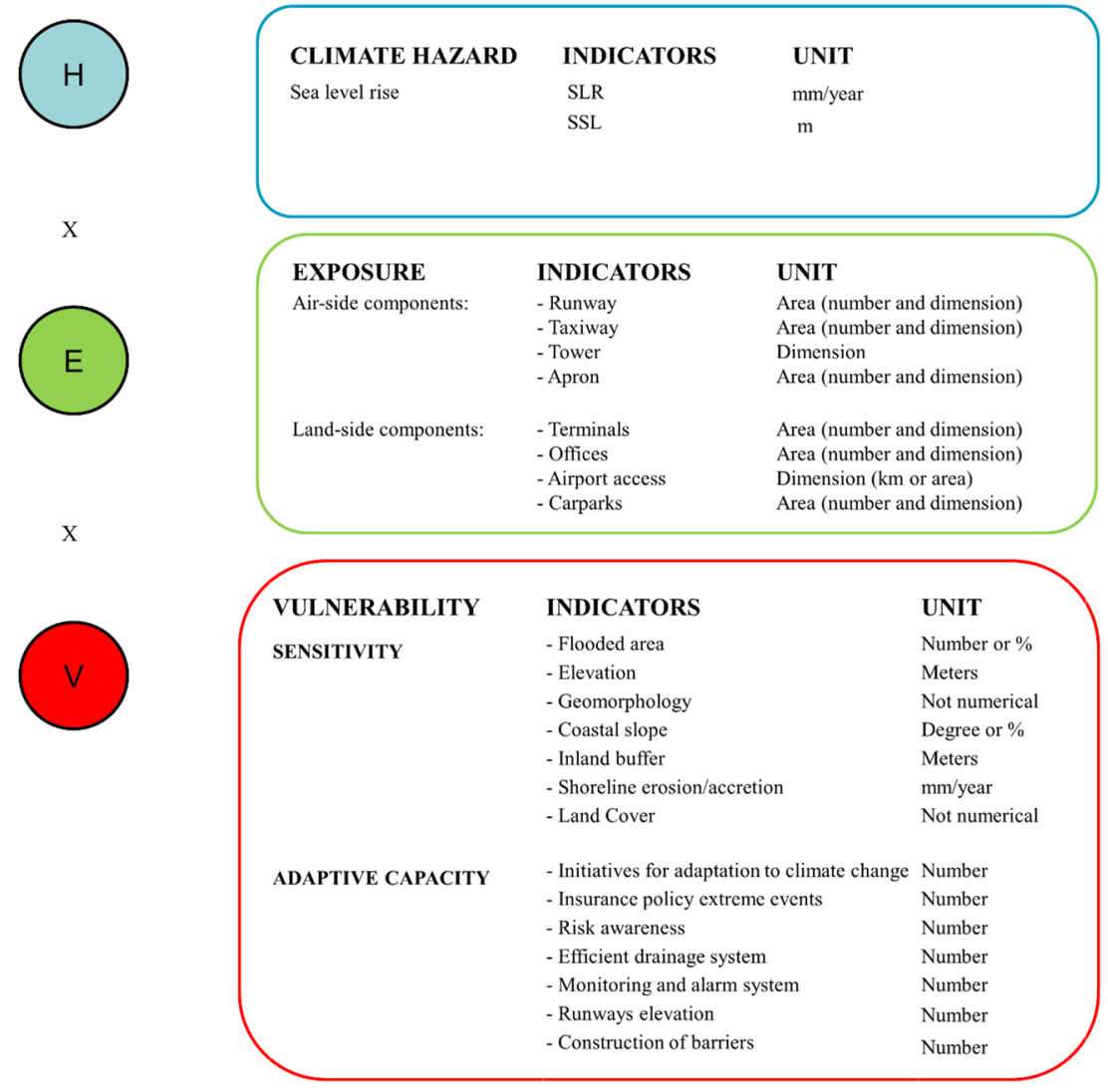

Fig. 4 Framework 3-Climate risk due to sea level rise

2015; Coffel et al. 2018). In fact, a research conducted by Gratton et al. (2020) over ten Greek airports, showed that the take-off distance for medium-sized aircraft increased by $2.7 \mathrm{~m}$ per year (reference period: 1955-2017) while for small-sized aircraft by $1.4 \mathrm{~m}$ per year. Additionally, extreme temperatures cause more pressure on local services, e.g., water and electricity for building cooling (Lopez 2016), and technical problems with radars for air traffic control (such was the case for Gatwick and Heathrow airports, in July 2019). Based on these main vulnerabilities for airports reported in the literature, we chose the sensitivity indicators. We selected physical factors such as the age and condition of the asset, since they influence the airports response to specific extreme events; we also considered sealed surfaces as they absorb more solar radiation, further increasing the air and surface temperatures (EEA 2016). The number of passengers, the number of flights and the accesses to car parks is also very useful information, which can be used to determine vulnerability. In fact, in a busy airport it is more difficult to manage impacts due to extreme weather events. Moreover, extreme temperatures can bring significant discomfort to outdoor workers and indoor workers with minimal access to cooling systems (Monioudi et al. 2018). On the other hand, to cope with thermal damages due to extreme temperature 
events, runways, taxiways and other structures should be resurfaced with heat resistant materials (Burbidge 2018). In areas where higher temperatures can pose a challenge to aircraft take-offs, adaptation measures include building longer runways (Burbidge 2018; Gratton et al. 2020) or performing intercontinental flights in the evening when temperatures drop, as in the Arizona case study (Coffel et al. 2018). Finally, the installation of roofs and walls with vegetation on airport structures are excellent green measures to mitigate the effects of extreme temperatures, to save energy and to reduce the flow of rainwater (Shafique and Kim 2017). Additional benefits obtained include a reduction in noise, an improvement in air quality and in the aesthetics of the building as well as other social, environmental and economic benefits (Shafique and Kim 2017). In framework 2 (in Fig. 3), as in case 1 , the climatic indicators were chosen based on precipitation thresholds that determine high impacts on airport components. Extreme rainfall events could compromise the drainage capacity of the airport, with an increase in flooding (Eurocontrol 2013). The longitudinal profile and the cross section of the runways are generally designed to minimize the risk of water accumulation (ICAO 2019). However, flooding of runways, taxiways and aprons has become more frequent in recent years because current drainage systems have often failed to cope with heavy rainfall. Flooding of a taxiway could force pilots to take longer taxi routes from terminals to runways, causing delays at one airport that affect many others (Borsky and Unterberger 2019). There are several factors that leave an airport more vulnerable to extreme rainfall: the presence of underground infrastructures such as parking or various access areas, which are more likely to suffer from flooding; the presence of impermeable surfaces as they reduce the potential for water infiltration of the soil, thus increasing the risk of flooding caused by greater runoff. Furthermore, the availability of historical data of the flooded areas could be useful to understand if the airports in question have been affected by similar events in the past. To cope with floods, airports need to implement adaptation strategies, which mainly concern the construction of efficient drainage systems as well as the development of adequate warning systems (Burbidge 2018; ICAO 2019). Many northern European airports have already implemented these strategies. For example, Norwegian airports have set new design standards for drainage systems by increasing drainage capacity by at least $50 \%$ over previous design standards (Eurocontrol 2018). In framework 3 (in Fig. 4), SLR and SSL indicators were selected to describe the coastal flooding. Many airports are built along the coasts or in floodplains to facilitate takeoff and landing, but these areas are more exposed to sea level rise and storm surges. Coastal flooding, as well as flooding from heavy precipitation, can affect runways, parking areas and other airport surfaces, damage buildings or other structures. Concerning the sensitivity indicators for sea level rise, we considered some of the factors defined for the calculation of the Coastal Vulnerability Index (CVI), proposed in the study of McLaughlin et al. (2010). We selected both morphological indices, which define the intrinsic characteristics of the coastal area on which the airport is located, and socio-economic factors (McLaughlin et al. 2010; Dismukes and Narra 2016; Hamid et al. 2019). The geological indicators refer to the resistance of the coasts and the tendency to erosion and their susceptibility to flooding. The elevation indicator is defined as the average elevation of a particular area above mean sea level and it is an important variable for identifying and estimating the extent of the area threatened by sea level rise according to future climate scenarios (McLaughlin et al. 2010). Generally, low coasts (with elevation $<5 \mathrm{~m}$ ) are more vulnerable to permanent and occasional flood events caused by more extreme storm surges and mean sea level rise. On the other hand, higher shores (elevation $>30 \mathrm{~m}$ ) are less susceptible to possible impacts of climate change (McLaughlin et al. 2010). Coastal geomorphology also plays an important role in coast assessment vulnerability because each morphology is 
characterized by some degree of resistance to erosion (Hereher 2015). For example, rocky shores are generally less vulnerable to flooding or erosion, while sedimentary coasts (e.g. sandy beach or reefs) are more vulnerable to shoreline changes (Rao et al. 2009; Gaki-Papanastassiou et al. 2010). Another key indicator is the coastal slope as it assesses the potential retreat speed of the coast: in general, gently sloping coasts can retreat faster than steeper regions (Rao et al. 2009). The inland buffer indicator describes the decreasing susceptibility of the coastal area to inundation and erosion (with increasing distances from the coastline), while indicator shoreline erosion/accretion is defined as the physical removal of sediment by wave and current action (Özyurt and Ergin 2009). Finally, as a socio-economic factor we considered the land cover indicator which defines the distribution of human activities and critical infrastructures in the coastal area. In fact, the presence of urban settlements or infrastructural systems (such as airports), makes the coast more vulnerable to damages related to erosion or flooding than the presence of natural environments. At the North Sea coast, where the impacts of sea level rise are more severe, the number of airports prone to flooding will double from 2030 to 2080 (Christodoulou and Demirel 2018). In fact, to contain the risk associated with coastal flooding, many airports, especially in northern Europe, have implemented grey adaptation strategies such as the construction of coastal barriers, higher runways and very efficient drainage systems. For example, Avinor Airport in Norway has established that future runways must be built at least $7 \mathrm{~m}$ above sea level. Other adaptation measures common to all three frameworks are the adhesion of airports to adaptation initiatives aimed at acquiring greater awareness of the risk of climate change impacts and adherence to insurance policies for extreme events, introducing tools for effective management of damages and losses.

\section{Conclusion}

This paper presents the theoretical frameworks for risk assessment related to extreme temperatures, extreme precipitations and sea level rise with a focus on Mediterranean airports. Airports located in the Mediterranean regions, in fact, will mainly have to face the risks associated with these climatic hazards. However, it is possible to replicate the application of the frameworks in other geographical contexts affected by the same risks. The impacts of climate change on the aviation sector are well known, but in Europe and especially in the Mediterranean basin, there is no clear methodology to assess climate risks for airports (Gratton et al. 2020). The method proposed here therefore aims to support stakeholders in conducting risk analyses in order to identify suitable adaptation strategies. Based on the state-of-the-art literature, the theoretical frameworks were constructed through the identification of specific indicators of hazard, exposure and vulnerability.

The next step of this work is the application of the proposed methodology to specific case studies. More specifically, our future plans include the application of these frameworks to the Italian airports most exposed to the climatic hazards examined, almost completely devoid of suitable adaptation strategies to climate risk (PNACC 2018). However, these studies require very specific data, which is often difficult to find, especially for aspects related to vulnerability, leading to inaccuracies in the methodology. In fact, the reliability of the results depends on the availability and quality of the input data. In the analysis of climatic hazards, for example, it is important to use robust time series or in the case of future analyzes, high-resolution climate models. Vulnerability indicators should be clear and well defined in order to describe the criticalities of the system considered. 
The illustrated methodology represents one of the first attempts to quantify risks in the airport environment and proposes an approach with the goal to define a specific risk for each hazard considered. Further research and applications in this area therefore need to be promoted, providing additional elements and cases studies.

Author contributions Carmela De Vivo, Paola Mercogliano and Giorgio Budillon contributed to the study conception and design. Material preparation and analysis were performed by Carmela De Vivo, Marta Ellena and Vincenzo Capozzi. The first draft of the manuscript was written by Carmela De Vivo and all authors commented on previous versions of the manuscript. Paola Mercogliano supervised the entire work. All authors read and approved the final manuscript.

Funding Open access funding provided by Università Parthenope di Napoli within the CRUI-CARE Agreement. Not applicable.

\section{Declarations}

Conflicts of interest The authors declare that they have no conflict of interest.

Data availability Not applicable.

Open Access This article is licensed under a Creative Commons Attribution 4.0 International License, which permits use, sharing, adaptation, distribution and reproduction in any medium or format, as long as you give appropriate credit to the original author(s) and the source, provide a link to the Creative Commons licence, and indicate if changes were made. The images or other third party material in this article are included in the article's Creative Commons licence, unless indicated otherwise in a credit line to the material. If material is not included in the article's Creative Commons licence and your intended use is not permitted by statutory regulation or exceeds the permitted use, you will need to obtain permission directly from the copyright holder. To view a copy of this licence, visit http://creativecommons.org/licenses/by/4.0/.

\section{References}

Admiraal H (2013) Underground space as invaluable resource for resilient cities, Proc. 13th World Confernece ACUUS Adv. Undergr Sp Dev ACUUS 2012:943-950. https://doi.org/10.3850/ 978-981-07-3757-3RP-056-P277

Alba SO, Manana M (2016) Energy research in airports: a review. Energies 9:1-19. https://doi.org/10.3390/ en9050349

Allen SK, Ballesteros-Canovas J, Randhawa SS, Singha AK, Huggel C, Stoffel M (2018) Translating the concepof climate risk into an assessment framework to inform adaptation planning: Insights from a pilot study of flood risk in Himachal Pradesh. Northern India, Environmental Science \& Policy 87:110. https://doi.org/10.1016/j.envsci.2018.05.013

Ashley RM, Balmfort DJ, Saul AJ, Blanskby JD (2005) Flooding in the future - predicting climate change, risks and responses in urban areas. Water Sci Technol 52:265-273. https://doi.org/10.2166/wst.2005. 0142

Åstebøl SO, Hvitved-Jacobsen T, Simonsen $\emptyset$ (2004) Sustainable stormwater management at Fornebu From an airport to an industrial and residential area of the city of Oslo, Norway. Sci Total Environ 334-335:239-249. https://doi.org/10.1016/j.scitotenv.2004.04.042

Borsky S, Unterberger C (2019) Bad weather and flight delays: the impact of sudden and slow onset weather events. Econ Transp 18:10-26. https://doi.org/10.1016/j.ecotra.2019.02.002

Burbidge R (2016) Adapting European airports to a changing climate. Transp Res Procedia 14:14-23. https://doi.org/10.1016/j.trpro.2016.05.036

Burbidge R (2018) Journal of air transport management adapting aviation to a changing climate: key priorities for action. J Air Transp Manag 71:167-174. https://doi.org/10.1016/j.jairtraman.2018.04.004 
Carrão H, Naumann G, Barbosa P (2016) Mapping global patterns of drought risk: an empirical framework based on sub-national estimates of hazard, exposure and vulnerability. Glob Environ Chang 39:108124. https://doi.org/10.1016/j.gloenvcha.2016.04.012

Christodoulou A, Demirel H (2018) Impacts of climate change on transport. A Focus on Airports, Seaports and Inland Waterways. https://doi.org/10.2760/378464

Climate-ADAPT platform, Sharing adaptation information across Europe. https://climate-adapt.eea.europa. $\mathrm{eu} /$

Coffel E, Horton R (2015) Climate change and the impact of extreme temperatures on aviation, ICNS 2015 - Innov. Oper. Implement. Benefits Integr. CNS Infrastructure, Conf. Proc. https://doi.org/10.1109/ ICNSURV.2015.7121288.

Coffel ED, Thompson TR, Horton RM (2018) The impacts of rising temperatures on aircraft takeoff performance. https://doi.org/10.1007/s10584-017-2018-9

Colin M, Palhol F, Leuxe A (2016) Adaptation of Transport Infrastructures and Networks to Climate Change. Transp Res Procedia. Elsevier, London, pp 86-95

Das S, Ghosh A, Hazra S, Ghosh T, Safra de Campos R, Samanta S (2020) Linking IPCC AR4 \& AR5 frameworks for assessing vulnerability and risk to climate change in the Indian Bengal Delta. Prog Disaster Sci 7:100110. https://doi.org/10.1016/j.pdisas.2020.100110

Dismukes DE, Narra S (2016) Identifying the vulnerabilities of working coasts supporting critical energy infrastructure. Water (switzerland). https://doi.org/10.3390/w8010008

Ellena M, Ricciardi G, Barbato G, Buffa A, Villani V, Mercogliano P (2020) Past and future hydrogeological risk assessment under climate change conditions over urban settlements and infrastructure systems: the case of a sub-regional area of Piedmont. Italy, Springer, Netherlands. https://doi.org/10.1007/ s11069-020-03925-w

EU-CIRCLE (2016) Impacts of climate change and extreme weather events on critical infrastructure state of the art review and taxonomy of existing knowledge . http://www.eu-circle.eu/for.

Eurocontrol (2013) Challenges of growth 2013 - Task 8 : Climate Change Risk and Resilience.

Eurocontrol (2018) European aviation in 2040 Challenges of Growth

European environment agency (EEA) (2016) Map book urban vulnerability to climate change Factsheets

European Environment Agency Report (EEA) (2017a) Climate change, impacts and vulnerability in Europe 2016 An indicator-based report

European environment agency report (EEA) (2017b) Climate change adaptation and disaster risk reduction in Europe.

European environment agency (EEA) (2019) European Aviation Environmental Report 2019.

Forzieri G, Bianchi A, e Silva FB, Marin M, Lavalle C, Feyen L (2016), Resilience of critical infrastructures in Europe to climate change, ECONADAPT Policy Workshop, Brussels https://econadapt.eu/sites/ default/files/2016-11/JRC_Feyen\%5B1\%5D.pdf

Forzieri G, Bianchi A, eSilva FB, Marin Herrera MA, Leblois A, Lavalle C, Aerts JCJH, Feyen L (2018) Escalating impacts of climate extremes on critical infrastructures in Europe. Glob Environ Chang 48: 97-107. https://doi.org/10.1016/j.gloenvcha.2017.11.007

Gaki-Papanastassiou K, Karymbalis E, Poulos SE, Seni A, Zouva C (2010) Coastal vulnerability assessment to sea-level rise bosed on geomorphological and oceanographical parameters: the case of Argolikos Gulf, Peloponnese, Greece. Hell J Geosci 45:109-122

Giorgi F (2006) Climate change hot-spots. Geophys Res Lett 33:1-4. https://doi.org/10.1029/2006GL0257 34

GIZ 2017, Risk supplement to the vulnerability sourcebook, available at https://www.adaptationcommunity. net/wp-content/uploads/2017/10/GIZ-2017_Risk-Supplement-to-the-Vulnerability-Sourcebook.pdf

Gratton G, Padhra A, Rapsomanikis S, Williams PD (2020) The impacts of climate change on Greek airports. Clim Change 160:219-231. https://doi.org/10.1007/s10584-019-02634-z

Hamid AIA, Din AHM, Yusof N, Abdullah NM, Omar AH, Abdul Khanan MF (2019) Coastal vulnerability index development: a review. Int. Arch Photogramm Remote Sens Spat Inf Sci ISPRS Arch 42:229235. https://doi.org/10.5194/isprs-archives-XLII-4-W16-229-2019

Hereher ME (2015) Coastal vulnerability assessment for Egypt's Mediterranean coast, geomatics. Nat Hazards Risk 6:342-355. https://doi.org/10.1080/19475705.2013.845115

Internation civil aviation organitation (ICAO) (2019) environment report, aviation and environment report. $4321-22$

IPCC 2014: Climate Change 2014: Impacts, adaptation, and vulnerability. Part A: Global and Sectoral Aspects. Contribution of Working Group II to the Fifth Assessment Report of the Intergovernmental Panel on Climate Change. Cambridge and New York: Cambridge University Press. Retrieved 03.05.2017 from http://www.ipcc.ch/report/ar5/wg2/

Yin J, Yin Z, Wang J, Xu S (2012) National assessment of coastal vulnerability to sea-level rise for the Chinese coast. J Coast Conserv 16:123-133. https://doi.org/10.1007/s11852-012-0180-9 
Keokhumcheng Y, Tingsanchali T, Clemente RS (2012) Flood risk assessment in the region surrounding the Bangkok Suvarnabhumi Airport. Water Int 37:201-217. https://doi.org/10.1080/02508060.2012. 687868

Kotopouleas A, Nikolopoulou M (2016) Thermal comfort conditions in airport terminals: Indoor or transition spaces? Build Environ 99:184-199. https://doi.org/10.1016/j.buildenv.2016.01.021

Lopez A (2016) Vulnerability of airports on climate change : an assessment methodology. Transp Res Procedia 14:24-31. https://doi.org/10.1016/j.trpro.2016.05.037

Marios G, Monica K, Zehra C, Turksezer I, Spinoni J, Mentaschi L, Feyen L (2019) Climate change and critical infrastructure-storms. European Union: Luxembourg. https://doi.org/10.2760/986436

Master Adapt (2018) Linee Guida, Principi E Procedure Standardizzate Per L'Analisi Climatica E La Valutazione Della Vulnerabilità a Livello Regionale E Locale.

McLaughlin S, Andrew J, Cooper G (2010) A multi-scale coastal vulnerability index: a tool for coastal managers? Environ Hazards 9:233-248. https://doi.org/10.3763/ehaz.2010.0052

Ministero dell'Ambiente e della tutela del territorio e del mare (Minamabiente) (2014) Guidelines for Climate Change Adaptation at the Local Level in the Alps. The Alpine Convention \& Ministero dell'Ambiente e della Tutela del Territorio e del Mare.

Monioudi I, Asariotis R, Becker A, Bhat C, Dowding-Gooden D, Esteban M, Feyen L, Mentaschi L, Nikolaou A, Nurse L, Phillips W, Smith D, Satoh M, Trotz UO, Velegrakis AF, Voukouvalas E, Vousdoukas MI, Witkop R (2018) Climate change impacts on critical international transportation assets of Caribbean Small Island Developing States (SIDS): the case of Jamaica and Saint Lucia. Reg Environ Chang 18:2211-2225. https://doi.org/10.1007/s10113-018-1360-4

Oppenheimer M, Campos M, Warren R, Birkmann J, Luber G, O’Neill B, Takahashi K(2014) IPCC-WGIIAR5-19. Emergent Risks and Key Vulnerabilities, Clim. Chang. 2014 Impacts, Adapt. Vulnerability. Part A Glob. Sect. Asp. Contrib. Work. Gr. II to Fifth Assess. Rep. Intergov. Panel Clim. Chang. 1039-1099.

Özyurt G, Ergin A (2009) Application of sea level rise vulnerability assessment model to selected coastal areas of Turkey. J Coast Res 1:248-251

Piano Nazionale di Adattamento ai Cambiamenti Climatici, PNACC 2018, https://www.minambiente.it/ sites/default/files/archivio/allegati/clima/pnacc.pdf

Ragazzo C (2017), Climate change risk assessment for the oil and gas industry : identification of potential impacts , vulnerabilities and adaptation strategies in coastal areas http://hdl.handle.net/10579/9704.

Rao KN, Subraelu P, Rao TV, Malini BH, Ratheesh R, Bhattacharya S, Ajai RAS (2009) Sea-level rise and coastal vulnerability: An assessment of Andhra Pradesh coast, India through remote sensing and GIS. J Coast Conserv 12:195-207. https://doi.org/10.1007/s11852-009-0042-2

Rowan E, Snow C, Choate A, Rodehorst B, Asam S, Hyman R, Kafalenos R, Gye A (2014) Indicator approach for assessing climate change vulnerability in transportation infrastructure. Transp Res Rec 2459:18-28. https://doi.org/10.3141/2459-03

Ryley T, Baumeister S, Coulter L (2020) Climate change influences on aviation: a literature review. Transp Policy 92:55-64. https://doi.org/10.1016/j.tranpol.2020.04.010

Shafique M, Kim R (2017) Application of green blue roof to mitigate heat island phenomena and resilient to climate change in urban areas: a case study from Seoul, Korea. J Water 1 Dev 33:165-170. https://doi. org/10.1515/jwld-2017-0032

Shah MAR, Renaud FG, Anderson CC, Wild A, Domeneghetti A, Polderman A, Votsis A, Pulvirenti B, Basu B, Thomson C, Panga D, Pouta E, Toth E, Pilla F, Sahani J, Ommer J, El Zohbi J, Munro K, M. Stefanopoulou M, Loupis M, Pangas N, Kumar P, Debele S, Preuschmann S, Zixuan W, (2020) A review of hydro-meteorological hazard, vulnerability, and risk assessment frameworks and indicators in the context of nature-based solutions. Int J Disaster Risk Reduct 50:101728. https://doi.org/10. 1016/j.ijdrr.2020.101728

Sistema Nazionale Protezione Ambiente (SNPA) 2018, Introduzione agli indicatori di impatto dei cambiamenti climatici:concetti chiave,indicatori candidati e criteri per la definizione di indicatori prioritari, ISPRA

Zebisch M, Schneiderbauer S, Renner K, Below T, Brossmann M, Ederer W, Schwan S (2017) Risk supplement to the vulnerability sourcebook http://www.adaptationcommunity.net/wp-content/uploads/2017/ 10/GIZ-2017_Risk-Supplement-to-the-Vulnerability-Sourcebook.pdf.

Publisher's Note Springer Nature remains neutral with regard to jurisdictional claims in published maps and institutional affiliations. 